AperTO - Archivio Istituzionale Open Access dell'Università di Torino

\title{
HUMAN POPULATION EFFECTS ON THE ULSOOR LAKE FISH SURVIVAL
}

\section{This is a pre print version of the following article:}

Original Citation:

\section{Availability:}

This version is available http://hdl.handle.net/2318/1686280

since 2019-01-30T14:37:40Z

Published version:

DOI:10.1142/S0218339018500274

Terms of use:

Open Access

Anyone can freely access the full text of works made available as "Open Access". Works made available under a Creative Commons license can be used according to the terms and conditions of said license. Use of all other works requires consent of the right holder (author or publisher) if not exempted from copyright protection by the applicable law. 


\section{Journal of Biological Systems Human population effects on the Ulsoor lake fish survival --Manuscript Draft--}

Manuscript Number:

Full Title:

Human population effects on the Ulsoor lake fish survival

Article Type:

Research Paper

Keywords:

Mathematical model; Human population; Organic pollutants; Dissolved oxygen;

Aquaculture; Ulsoor lake; Stability.

Corresponding Author:

Arvind Kumar Misra, PhD

BHU VARANASI

INDIA

Corresponding Author Secondary

Information:

Corresponding Author's Institution:

BHU VARANASI

Corresponding Author's Secondary Institution:

First Author:

Arvind Kumar Misra, PhD

First Author Secondary Information:

Order of Authors:

Arvind Kumar Misra, PhD

Pankaj Kumar Tiwari

Iulia Martina Bulai

Francesca Bona

Ezio Venturino

Order of Authors Secondary Information:

\begin{tabular}{ll} 
Abstract: & $\begin{array}{l}\text { In this paper, we introduce a model to study the effects of human populations on fish } \\
\text { survival in aquatic media. Directly this occurs by fishing. Indirectly instead this is } \\
\text { related to other human actions that lead to organic pollution and consequently low } \\
\text { dissolved oxygen levels, thereby harming the aquatic fauna. Mathematically, we } \\
\text { consider various nonlinear processes involving human population, organic pollutants, } \\
\text { bacteria, dissolved oxygen and fish population. In the present study, our aim is to } \\
\text { investigate the effect of depleted level of dissolved oxygen on the survival of fish } \\
\text { populations in such an aquatic system. The case study in consideration is represented } \\
\text { by the Ulsoor lake, Bengaluru, India. Into it, huge amounts of sewage were discharged } \\
\text { and resulted in reduction of dissolved oxygen level and massive fish killing. Equilibria } \\
\text { are analyzed for feasibility and stability, substantiated via numerical simulations. Global } \\
\text { sensitivity analysis identifies the important parameters having a significant impact on } \\
\text { the fish population. The results show that increase in human population may decrease } \\
\text { fish population in the system to very low values. However, by controlling additional } \\
\text { dissolved organic loads coming from domestic sewage, farm waste and many other } \\
\text { sources, the level of dissolved oxygen can be brought back to values that allow fish } \\
\text { survival. Maintaining it at these levels would preserve the ecosystem. }\end{array}$ \\
\hline $\begin{array}{l}\text { Joydev Chattopadhyay } \\
\text { joydev@isical.ac.in }\end{array}$ \\
\hline $\begin{array}{l}\text { Samrat Chatterjee } \\
\text { samrat.chatterjee@thsti.res.in }\end{array}$ \\
\hline $\begin{array}{l}\text { B. W. Kooi } \\
\text { bob.kooi@vu.nl }\end{array}$ \\
$\begin{array}{ll}\text { Horst Malchow } \\
\text { malchow@uos.de }\end{array}$ \\
\hline
\end{tabular}




\title{
Human population effects on the Ulsoor lake fish survival
}

\author{
Pankaj Kumar Tiwari ${ }^{\mathrm{a}}$, Iulia Martina Bulai ${ }^{\mathrm{a}}$, Francesca Bona ${ }^{\mathrm{b}}$, \\ Ezio Venturino ${ }^{a}$ and Arvind Kumar Misra ${ }^{\mathrm{c}, *}$ \\ a Dipartimento di Matematica "Giuseppe Peano", via Carlo Alberto 10, 10123 \\ Torino, Università di Torino, Italy; Member of the INdAM research group GNCS \\ ${ }^{\mathrm{b}}$ DBIOS, University of Turin, via Accademia Albertina 13, 10123 Turin, Italy \\ ${ }^{\mathrm{c}}$ Department of Mathematics, Institute of Science, Banaras Hindu University, \\ Varanasi 221005, India
}

\begin{abstract}
In this paper, we introduce a model to study the effects of human populations on fish survival in aquatic media. Directly this occurs by fishing. Indirectly instead this is related to other human actions that lead to organic pollution and consequently low dissolved oxygen levels, thereby harming the aquatic fauna. Mathematically, we consider various nonlinear processes involving human population, organic pollutants, bacteria, dissolved oxygen and fish population. In the present study, our aim is to investigate the effect of depleted level of dissolved oxygen on the survival of fish populations in such an aquatic system. The case study in consideration is represented by the Ulsoor lake, Bengaluru, India. Into it, huge amounts of sewage were discharged and resulted in reduction of dissolved oxygen level and massive fish killing. Equilibria are analyzed for feasibility and stability, substantiated via numerical simulations. Global sensitivity analysis identifies the important parameters having a significant impact on the fish population. The results show that increase in human population may decrease fish population in the system to very low values. However, by controlling additional dissolved organic loads coming from domestic sewage, farm waste and many other sources, the level of dissolved oxygen can be brought back to values that allow fish survival. Maintaining it at these levels would preserve the ecosystem.
\end{abstract}

Key words: Mathematical model, Human population, Organic pollutants, Dissolved oxygen, Aquaculture, Ulsoor lake, Stability.

\footnotetext{
* Corresponding author.

Email address: akmisra@bhu.ac.in (Arvind Kumar Misra).
}

Preprint submitted to Journal of Biological Systems

20 March 2018 


\section{Introduction}

Water has always played a key role in the survival of ecosystems. Access to its clean and abundant supplies will become in the next decades a fundamental issue for the whole of humanity. In view of population growth, water scarcity will become more pronounced [1], this also being to contamination by anthropogenic activities as well as industrial and agricultural seepage. In addition, eutrophication cause foul odors and reduce dissolved oxygen (DO) to such low levels that render aquatic ecosystem life difficult [2]. In turn, leaching of polluted waters into the deep layers of the soil have also affected groundwater reserves, thereby rendering source waters unsafe for human consumption and for many other activities such as irrigation and industrial use. Thus degraded water quality compounds with water scarcity to limit the quantity available both for human populations as well as for the ecosystems [3].

Because of rising population levels and living standards, there is an ever increasing demand for clean water. The Earth's water supply stays the same in time, but human activities may alter its natural cycle, by contaminating it with chemicals and other substances [4,5]. In this respect, human population, agriculture and industries constitute relevant factors for the increase in organic pollutants and eutrophication, which is even exacerbated in lentic ecosystems such as lakes [6], leading to a decrease in DO, thus exerting an overall destabilizing effect on the aquatic ecosystem [7]. Indeed bacteria and other aquatic micro-organisms use DO to decompose organic pollutants [8], an important step of the ecosystem for functioning.

Starting from the classical study [9], modeling of water pollution has attracted the worldwide researchers attention along the years [10-16]. If the organic pollutants are continuously dumped into the waters, the DO concentration drops to very low values and threatens the survival of aquatic organisms [17], this phenomenon being much amplified when occurring in combination with eutrophication [18], but it can be maintained at acceptable levels by controlling the cumulative discharge of these pollutants [19]. Modeling of the depletion of DO due to organic pollutants-bacteria interactions has been considered in $[20,21]$. Likewise, nutrients leaching through agricultural runoff in the water bodies such as lakes and ponds, enhances the growth of aquatic plants and algae. Shukla et al. [22] and Misra [23] have proposed mathematical models to study the effect of algal bloom on the depletion of DO in a lake by considering the constant input rate of nutrients and Holling type II and Holling type III interactions between concentration of nutrients and the density of algae, respectively. These studies have suggested that the increase in the inflow rate of nutrients not only enhances the growth of algae but also depletes the level of DO in the lakes and thus threatens the survival of aquatic populations. 
Shukla et al. [17] studied the effect of organic pollutants on the survival of fish in water bodies. They have considered constant input rate of organic pollutants in the system through various sources such as domestic sewage, industries, agriculture, etc. Further, they assumed that the growth rate of fish population wholly depends on the concentration of DO in the system. They have shown that the concentration of DO decreases due to various biodegradation and biochemical processes and consequently the survival of fish population is threatened. They also found that if the organic pollutants continue to be discharged into the water body, the concentration of DO may become negligibly small and the fish population is doomed to extinction. Recently, the effects of organic and inorganic pollutants on the survival of fish in water bodies has been studied by Tiwari et al. [24]. They have not considered the effect of human population in the system explicitly. The results of their study showed that the release of organic and inorganic pollutants into the aquatic systems must be controlled by the global community in order to maintain the quality of water and preserve the life of fish in the aquatic media. Here, our aim is to explicitly introduce the effects that human population entail on the fish survival in lakes in which fishery is a primary resource. For modeling purpose, we assume that human population has two main influences on the aquatic ecosystem. On one hand, they pollute the water discharging into it their wastes coming from various sources (e.g. domestic sewage, industry, agriculture). On the other one, they feed on the fish living in the water body. We focus on one single consequence of pollution: the oxygen depletion. The outcome is that both human actions augment the fish mortality. The decrease of fish induces also a decrease in oxygen consumption, so there might be a general benefit for water quality. The model aims at ultimately investigating whether this hypothesis may indeed become true.

The rest of the paper is organized as follows: in the next section, the situation of the Ulsoor lake, Bengaluru, India is presented. In Section 3, the basic model is described. In Section 4, we have obtained the possible equilibria of the model and analyzed their stability behavior. In Section 5, some numerical simulations of the model are performed while global sensitivity analysis is carried out in Section 6 to identify important model parameters. Finally, a brief discussion in Section 7 concludes the paper.

\section{The Ulsoor lake, Bengaluru, India}

Bengaluru district is located in the heart of South Deccan of Peninsular India. It is situated in the south-eastern corner of Karnataka state (12039'13018' N latitude and 77022'-77052' E longitude) with a geographical area of about 2,191 $\mathrm{km}^{2}$ and an average elevation of $900 \mathrm{~m}$ above sea level. It has

two rainy seasons from June to September and October to November coming 
one after the other but with opposite wind regime, corresponding to southwest and north-east monsoons. The mean monthly relative humidity is lowest in the month of March (44\%) and high during the month of June to October, being between 80 to $85 \%$ on an average [25]. Formerly in Bengaluru there were about 262 lakes of which 81 still exist today. These lakes form a chain of streams, which finally join either river Arkavathi or river Dakshina Pinakini. Rainwater is stored in lakes through which ground water aquifers get eventually recharged. Man-made lakes of the district were constructed for drinking, agriculture, recreation and fishing purposes. Regrettably, many lakes and ponds have already disappeared due to various anthropogenic activities and pressures due to unplanned urbanization and expansion. Surviving lakes are reduced to severely impacted waterbody due to direct discharge of industrial effluents, sewage and unregulated dumping of solid wastes. Ulsoor is one of the city lakes spreading over an area of about 50 hectares. The catchment area of the lake is $1.5 \mathrm{~km}^{2}$, the current depth ranges from approximately 1.8 to $2.1 \mathrm{~m}$ in the middle and 0.9 to $1.2 \mathrm{~m}$ in the periphery and has capacity of storing 11,000 million litres of water. It has a park in its vicinity, a corporation swimming pool adjacent to the lake, three islands and receives direct industrial and domestic wastewaters from the surrounding area of Tannery road, Ulsoor. The Ulsoor lake drain enters the lake in the north and excess water overflows from the southeast canal [26].

In recent years, the Ulsoor lake has been plagued with pollution due to the release of untreated sewage with high amount of organic content and choked with water hyacinth. With temperatures rising in the city, there is more biological activity and a reduction of oxygen levels in the water, which caused the massive fish killing. The fish mass deaths are also due to the lake's stagnant water. There are several indications that the problem of pollution in the city's ecosystem runs deeper. The building of a floating restaurant at Ulsoor lake, further damage the lake's ecological balance. Thousands of dead fish have been discovered floating on the shores of the Ulsoor Lake in March 2016 [27]. The whole of the lakes' system in Bengaluru has been destroyed for the past few decades, because colonies discharge their effluent in the lakes. Flowing of unrestricted sewage into the lake form thick layers, which cut off the oxygen for the fish [28]. The lake had suffered because of the immersing of idols and unrestricted fishing in addition to too high contamination. Storm water drains coming from J.C. Nagar, Doddakunte and Assaye road bring water into the lake. A study on water quality of the lake shows that DO was very high during the day and low at night (range $0.1 \mathrm{mg} / \mathrm{L}$ to $4.4 \mathrm{mg} / \mathrm{L}$ ). Phosphate and nitrogen content was found to be higher and chlorophyll content was unusually high. The minimum and maximum content of phosphate was $2.02 \mathrm{mg} / \mathrm{L}$ and $2.49 \mathrm{mg} / \mathrm{L}$ respectively, while nitrogen was $2.41 \mathrm{mg} / \mathrm{L}$ and $3.7 \mathrm{mg} / \mathrm{L}$ and chlorophyll $583 \mathrm{mg} / \mathrm{m}^{3}$ and $1026 \mathrm{mg} / \mathrm{m}^{3}$. The concentrations of zinc, cadmium, chromium, lead and copper were found to be very high in sludge samples. The concentration of heavy metals ranged from $130 \mathrm{mg} / \mathrm{kg}$ to 
$95300 \mathrm{mg} / \mathrm{kg}[29]$.

There are three drains joining Ulsoor lake at different points, the first drain starting from the Madras Engineering Group, a kilometre from the lake. The second drain starts from Jeevanahalli, around two kms from the lake. The third starts from Doddigunta and traverses through Kattariyamma garden, Godhandappa garden, Munivenkattappa garden, Muthamma garden and New Corporation colony. All these areas are slums, which are within a kilometre from the lake. These drains carry wastewater from residential areas into the lake. During rainy season the storm water and sewage water flows into the Ulsoor lake. Blue green algae - microcystis was observed to spread from the surface to the bottom of the lake. This algae is toxic and utilises DO in the night, while releasing oxygen during the day. Aquatic plants and fish have been highly affected with only a few fish varieties remaining. Mass fish deaths in Bengaluru's lakes are the consequence of extreme mismanagement of the city's fragile and ecologically vital lakes and wetlands. The fish choked to death after oxygen levels in the water suddenly fell sharply. Steady flow of untreated sewage into the lake and high levels of certain toxic substances could have depleted oxygen levels. The physico-chemical characteristics of Ulsoor lake reveals depletion of oxygen, high turbidity and organic contents, BOD and ammonia toxicity [30]. Fish usually require a minimum of $5 \mathrm{mg} / \mathrm{L}$ of DO. They can tolerate below $2 \mathrm{mg} / \mathrm{L}$ for short periods, but they will start dying when the DO drops below $1 \mathrm{mg} / \mathrm{L}$ [31]. The summer heat could have enhanced the effect but Ulsoor is an indicator of environmental stress, declining of aquatic ecosystems health and water quality problems. Recurring episodes of fish mortality, algal bloom, profuse growth of invasive exotic weeds, introduction and rearing of exotic species highlight administrative mismanagement. Despite significant service to the local geography, wetlands are being encroached and polluted by senseless and irresponsible urban decisions [32,33].

\section{The mathematical model}

It is apparent from the study of Ulsoor lake, Bengaluru, India, that the drainage of sewage from city in the lake significantly deteriorates the quality of its water. Due to insufficient capacity of sewage treatment plants in Bengaluru, the water of the lake experienced a huge drop in the level of DO and massive fish killing. Here, we propose a nonlinear mathematical model which reflects the situations of Ulsoor lake.

Let $N$ be the density of human population in the lake watershed at any time $t>0$. Let $T$ be the water concentration of organic pollutants, $B$ be the density of bacteria, $O$ be the concentration of DO and $F$ be the density of fish population in the lake. It is assumed that the human population follows 
logistic growth and also partially depends on the fish population [34-37]. The discharge rate of organic pollutants in the water body due to domestic sewage is assumed to be human-population-dependent. On the other hand, the average input rate of organic pollutants through all other means is assumed for sake of simplicity to be a constant, $Q[8,17]$, a strong assumption. The organic pollutants are degraded by bacteria present in the system while the bacteria multiply by feeding on them. Bacteria die naturally and also experience intraspecific competition.

The level of DO in the water body increases due to air-water interaction and due to photosynthesis by benthic and pelagic algae [2] and experiences natural depletion. Further, the DO is also linked to the bacteria, since upon lysis they break down back into organic matter, but in this process, DO is consumed [38]. The growth rate of fish is assumed to be wholly dependent on the concentration of DO in the water body [17]. The main reason behind this assumption is that we assume that food and space are sufficient to support the life of fish population. But, due to continuous inflow of pollutants in the system, the organic load increases and the concentration of DO decreases, conditions that ultimately affect the growth and survival of fish population. Fish die naturally as well as due to their intraspecific, interspecific competition and predation. The fish population decreases also due to human fishing activities. We thus consider the following mathematical model:

$$
\begin{aligned}
& \frac{d N}{d t}=r N\left(1-\frac{N}{K}\right)+\theta \alpha F N \\
& \frac{d T}{d t}=Q+\delta N-\alpha_{0} T-\frac{k_{1} T B}{k_{12}+k_{11} T} \\
& \frac{d B}{d t}=\frac{\lambda_{1} k_{1} T B}{k_{12}+k_{11} T}-\alpha_{1} B-\lambda_{10} B^{2} \\
& \frac{d O}{d t}=q-\alpha_{2} O-\lambda_{11} \alpha_{1} B O-\beta O F \\
& \frac{d F}{d t}=\theta_{1} \beta O F-\alpha_{3} F-\beta_{10} F^{2}-\alpha F N .
\end{aligned}
$$

All the parameters involved in the model (1) are assumed to be nonnegative. The first equation describes the evolution of the human population, which is assumed to be logistic and enhanced by the fishing availability, incorporated into the model via a suitable "predation" term. The second equation states that organic pollutants flow in at constant rate, come also from human activities and therefore are proportional to the density of human population, second term. They are naturally depleted and are degraded by bacteria, following a Holling type II law. Note that the third term expresses the fact that pollutants can be washed out, or sink and disappear from the ecosystem by getting immobilized at the bottom of the water body; in both cases, they 
are removed from the water at rate $\alpha_{0}$. The third equation represents the bacteria dynamics. They thrive by decomposing the organic pollutants and feeding upon them, this being modeled via a saturating function. They die naturally, second term, and are also subject to intraspecific competition for the resources, which is expressed by the last term.

The fourth equation accounts for the changes in DO concentration, being constantly supplied and naturally depleted. Oxygen is also consumed by the bacteria, because it is needed in their decomposition process after their death, or also when they are predated by higher trophic aquatic organisms, such as protozoa. These features are modeled in the second term. Fish also use oxygen to thrive. As a first approximation, to keep the system tractable, we model this uptake via a mass action law, which is a common functional expression in population models. The last equation for the fish accounts for their survival and reproduction, activities that both need oxygen. Fish are subject to mortality, either natural or due to competition for resources, and are captured by fishing. The role of oxygen in this equation is relevant in influencing fish mortality, since its absence implies that the population decays and disappears from the ecosystem.

The biological meanings of all the variables and parameters of the model (1) are summarized in Table 1. To have a meaningful model, the third equation of system (1) must ensure that the bacteria thrive, so that the following condition must be satisfied:

$$
\lambda_{1} k_{1}-k_{11} \alpha_{1}>0
$$

\section{Mathematical analysis}

\subsection{Equilibrium analysis}

The model (1) exhibits the following eight non-negative equilibria:

1. The human-bacteria-fish-free equilibrium $E_{1}\left(0, \frac{Q}{\alpha_{0}}, 0, \frac{q}{\alpha_{2}}, 0\right)$, which is always feasible.

2. The human-fish-free equilibrium $E_{2}\left(0, T_{2}, B_{2}, O_{2}, 0\right)$, where $B_{2}=\frac{1}{\lambda_{10}}\left(\frac{\lambda_{1} k_{1} T_{2}}{k_{12}+k_{11} T_{2}}-\alpha_{1}\right)$, $O_{2}=\frac{q}{\alpha_{2}+\lambda_{11} \alpha_{1} B_{2}}$ and $T_{2}$ is a positive root of the following equation: 


$$
\frac{1}{\lambda_{10}}\left(\frac{\lambda_{1} k_{1} T}{k_{12}+k_{11} T}-\alpha_{1}\right)-\frac{Q-\alpha_{0} T}{k_{1}}\left(k_{11}+\frac{k_{12}}{T}\right)=0
$$

Equation (3) has a unique positive root in the interval $\left(0, \frac{Q}{\alpha_{0}}\right)$ provided

$$
Q\left(\lambda_{1} k_{1}-k_{11} \alpha_{1}\right)-k_{12} \alpha_{1} \alpha_{0}>0
$$

Here, it may be noted that $B$ is positive if

$$
\left(\lambda_{1} k_{1}-k_{11} \alpha_{1}\right) T_{2}-k_{12} \alpha_{1}>0
$$

The equilibrium $E_{2}$ is feasible if conditions (4) and (5) hold.

3. The human-bacteria-free equilibrium $E_{3}\left(0, \frac{Q}{\alpha_{0}}, 0, O_{3}, F_{3}\right)$, where $F_{3}=$ $\frac{1}{\beta_{10}}\left(\theta_{1} \beta O_{3}-\alpha_{3}\right)$ and $O_{3}$ is a positive root of the following equation:

$$
\theta_{1} \beta^{2} O^{2}-\left(\beta \alpha_{3}-\beta_{10} \alpha_{2}\right) O-q \beta_{10}=0
$$

Equation (6) has a positive and a negative roots. For having a positive value of $F$, we must impose

$$
\theta_{1} \beta O_{3}-\alpha_{3}>0
$$

The equilibrium $E_{3}$ is feasible if condition (7) holds.

4. The human-free equilibrium $E_{4}\left(0, T_{4}, B_{4}, O_{4}, F_{4}\right)$, where $T_{4}=T_{2}, B_{4}=B_{2}$, $F_{4}=\frac{1}{\beta_{10}}\left(\theta_{1} \beta O_{4}-\alpha_{3}\right)$ and $O_{4}$ is positive root of the following equation:

$$
\theta_{1} \beta^{2} O^{2}-\left(\beta \alpha_{3}-\beta_{10} \alpha_{2}-\lambda_{11} \alpha_{1} \beta_{10} B_{4}\right) O-q \beta_{10}=0
$$

Equation (8) has a positive and a negative roots. The equilibrium $E_{4}$ is feasible provided the following conditions hold:

$$
\begin{aligned}
Q\left(\lambda_{1} k_{1}-k_{11} \alpha_{1}\right)-k_{12} \alpha_{1} \alpha_{0} & >0 \\
\left(\lambda_{1} k_{1}-k_{11} \alpha_{1}\right) T_{4}-k_{12} \alpha_{1} & >0, \\
\theta_{1} \beta O_{4}-\alpha_{3} & >0 .
\end{aligned}
$$


5. The bacteria-fish-free equilibrium $E_{5}\left(K, \frac{Q+\delta K}{\alpha_{0}}, 0, \frac{q}{\alpha_{2}}, 0\right)$, which is always feasible.

6. The fish-free equilibrium $E_{6}\left(K, T_{6}, B_{6}, O_{6}, 0\right)$, where $B_{6}=\frac{1}{\lambda_{10}}\left(\frac{\lambda_{1} k_{1} T_{6}}{k_{12}+k_{11} T_{6}}-\alpha_{1}\right)$, $O_{6}=\frac{q}{\alpha_{2}+\lambda_{11} \alpha_{1} B_{6}}$ and $T_{6}$ is positive root of the following equation:

$$
\frac{1}{\lambda_{10}}\left(\frac{\lambda_{1} k_{1} T}{k_{12}+k_{11} T}-\alpha_{1}\right)-\frac{(Q+\delta K)-\alpha_{0} T}{k_{1}}\left(k_{11}+\frac{k_{12}}{T}\right)=0 .
$$

Equation (12) has a unique positive root in the interval $\left(0, \frac{Q+\delta K}{\alpha_{0}}\right)$ provided

$$
(Q+\delta K)\left(\lambda_{1} k_{1}-k_{11} \alpha_{1}\right)-k_{12} \alpha_{1} \alpha_{0}>0
$$

Also, for positivity of $B_{6}$, we must have

$$
\left(\lambda_{1} k_{1}-k_{12} \alpha_{1}\right) T_{6}-k_{12} \alpha_{1}>0
$$

The equilibrium $E_{6}$ is feasible if conditions (13) and (14) hold.

7. The bacteria-free equilibrium $E_{7}\left(N_{7}, T_{7}, 0, O_{7}, F_{7}\right)$, where $N_{7}=\frac{K}{r}(r+$ $\left.\theta \alpha F_{7}\right), T_{7}=\frac{Q+\delta N_{7}}{\alpha_{0}}, F_{7}=\frac{r\left\{\theta_{1} \beta O_{7}-\left(\alpha_{3}+\alpha K\right)\right\}}{r \beta_{10}+\theta \alpha^{2} K}$ and $O_{7}$ is a positive root of the following equation:

$$
\begin{gathered}
\theta_{1} \beta^{2} O^{2}-\left\{\beta\left(\alpha_{3}+\alpha K\right)-\alpha_{2}\left(\beta_{10}+\frac{\theta \alpha^{2} K}{r}\right)\right\} O \\
-q\left(\beta_{10}+\frac{\theta \alpha^{2} K}{r}\right)=0
\end{gathered}
$$

Equation (15) has a positive and a negative roots. The equilibrium $E_{7}$ is feasible provided

$$
\theta_{1} \beta O_{7}-\left(\alpha_{3}+\alpha K\right)>0
$$

8. The coexistence equilibrium $E^{*}\left(N^{*}, T^{*}, B^{*}, O^{*}, F^{*}\right)$, where $N^{*}, T^{*}, B^{*}$, 
$O^{*}$ and $F^{*}$ are positive solutions of the equilibrium equations. From the first equilibrium equation of (1), we have

$$
N=\frac{K}{r}(r+\theta \alpha F)
$$

From the third equilibrium equation of system (1), we have

$$
B=\frac{1}{\lambda_{10}}\left(\frac{\lambda_{1} k_{1} T}{k_{12}+k_{11} T}-\alpha_{1}\right)
$$

Using equation (17) in the last equilibrium equation of system (1), we have

$$
F=\frac{r\left\{\theta_{1} \beta O-\left(\alpha_{3}+\alpha K\right)\right\}}{r \beta_{10}+\theta \alpha^{2} K}
$$

Now, using equations (17)-(19) in the second equilibrium equation of system (1), we have

$$
\begin{aligned}
Q+\delta K+\frac{\delta \alpha K \theta\left\{\theta_{1} \beta O-\left(\alpha_{3}+\alpha K\right)\right\}}{r \beta_{10}+\theta \alpha^{2} K}-\alpha_{0} T \\
-\frac{1}{\lambda_{10}} \frac{k_{1} T}{k_{12}+k_{11} T}\left(\frac{\lambda_{1} k_{1} T}{k_{12}+k_{11} T}-\alpha_{1}\right)=0 .
\end{aligned}
$$

Again, using equations (17) and (19) in the fourth equilibrium equation of system (1), we have

$$
\begin{aligned}
q-\alpha_{2} O-\frac{1}{\lambda_{10}}( & \left.\frac{\lambda_{1} k_{1} T}{k_{12}+k_{11} T}-\alpha_{1}\right) \lambda_{11} \alpha_{1} O \\
& -\frac{r \beta O\left\{\theta_{1} \beta O-\left(\alpha_{3}+\alpha K\right)\right\}}{r \beta_{10}+\theta \alpha^{2} K}=0 .
\end{aligned}
$$

From equation (20), we note the following:

(i) At $O=\frac{\alpha_{3}+\alpha K}{\theta_{1} \beta}$, there exists a unique positive value of $T$ (say, $T_{1}$ ) in the interval $\left(\frac{k_{12} \alpha_{1}}{\lambda_{1} k_{1}-k_{11} \alpha_{1}}, \frac{Q+\delta K}{\alpha_{0}}\right)$, provided $\left(\lambda_{1} k_{1}-k_{11} \alpha_{1}\right)(Q+\delta K)-k_{12} \alpha_{1} \alpha_{0}>0$.

(ii) At $T=\frac{k_{12} \alpha_{1}}{\lambda_{1} k_{1}-k_{11} \alpha_{1}}$, 


$$
\begin{aligned}
& O=\frac{\alpha_{3}+\alpha K}{\theta_{1} \beta}-\frac{r \beta_{10}+\theta \alpha^{2} K}{\theta_{1} \beta \delta \alpha K \theta} \frac{\left(\lambda_{1} k_{1}-k_{11} \alpha_{1}\right)(Q+\delta K)-k_{12} \alpha_{1} \alpha_{0}}{\left(\lambda_{1} k_{1}-k_{11} \alpha_{1}\right)}<\frac{\alpha_{3}+\alpha K}{\theta_{1} \beta} . \\
& \text { (iii) } \frac{d O}{d T}>0 \text { in the interval }\left(\frac{k_{12} \alpha_{1}}{\lambda_{1} k_{1}-k_{11} \alpha_{1}}, \frac{Q+\delta K}{\alpha_{0}}\right) .
\end{aligned}
$$

Similarly, from equation (21), we note the following:

(i) At $T=\frac{k_{12} \alpha_{1}}{\lambda_{1} k_{1}-k_{11} \alpha_{1}}$, equation (21) reduces to a quadratic equation in $\mathrm{O}$, which has a unique positive root, say $O_{1}$, in the interval $\left(\frac{\alpha_{3}+\alpha K}{\theta_{1} \beta}, \frac{q}{\alpha_{2}}\right)$,

provided $\theta_{1} \beta q-\alpha_{2}\left(\alpha_{3}+\alpha K\right)>0$.

(ii) At $O=\frac{\alpha_{3}+\alpha K}{\theta_{1} \beta}$, we get a value of $T$, say

$$
\begin{aligned}
& T_{2}=\frac{k_{12}\left(\alpha_{1}+p\right)}{\lambda_{1} k_{1}-k_{11}\left(\alpha_{1}+p\right)} \text {, where } p=\frac{\lambda_{10} \theta_{1} \beta}{\lambda_{11} \alpha_{1}\left(\alpha_{3}+\alpha K\right)}\left(q-\frac{\alpha_{2}\left(\alpha_{3}+\alpha K\right)}{\theta_{1} \beta}\right) . \\
& \text { (iii) } \frac{d O}{d T}<0 .
\end{aligned}
$$

From the above facts, it is clear that there exists a unique value of $\left(O^{*}, T^{*}\right)$ in the interior of first quadrant if $T_{1}<T_{2}$. The intersection of the isoclines (20) and (21) is shown in Fig. 1. Now, from equations (17)-(19), we can get positive values of $N^{*}, B^{*}$ and $F^{*}$, respectively. Thus, the coexistence equilibrium $E^{*}$ is feasible if the following conditions are satisfied:

$$
\begin{aligned}
(Q+\delta K)\left(\lambda_{1} k_{1}-k_{11} \alpha_{1}\right)-k_{12} \alpha_{1} \alpha_{0} & >0, \\
\left(\lambda_{1} k_{1}-k_{11} \alpha_{1}\right) T^{*}-k_{12} \alpha_{1} & >0 \\
\theta_{1} \beta O^{*}-\left(\alpha_{3}+\alpha K\right) & >0 \\
T_{2} & >T_{1} .
\end{aligned}
$$

\subsection{Stability analysis}

In this section, we study the stability of all equilibria of the model (1). We study the global asymptotic stability of the coexistence equilibrium $E^{*}$ in the region defined in the following lemma [39-41].

Lemma 1. The region of attraction for all solutions initiating in the positive orthant is given by the set $\Omega$ :

$$
\begin{gathered}
\Omega=\left\{(N, T, B, O, F): 0 \leq N<N_{m} ; 0 \leq T \leq T_{m} ; 0 \leq B \leq B_{m}\right. \\
\left.0 \leq O \leq O_{m} ; 0 \leq F \leq F_{m}\right\}
\end{gathered}
$$


where

$$
\begin{aligned}
& N_{m}=\frac{K}{r}\left(r+\theta \alpha F_{m}\right), T_{m}=\frac{Q+\delta N_{m}}{\alpha_{0}}, B_{m}=\frac{\lambda_{1} k_{1}\left(Q+\delta N_{m}\right)}{\lambda_{10}\left\{k_{12} \alpha_{0}+k_{11}\left(Q+\delta N_{m}\right)\right\}} \\
& O_{m}=\frac{q}{\alpha_{2}}, F_{m}=\frac{\theta_{1} \beta q}{\beta_{10} \alpha_{2}}
\end{aligned}
$$

The proof of this theorem is given in Appendix-A.

Theorem 1. 1. The equilibria $E_{1}$ and $E_{2}$ are always unstable.

2. The equilibria $E_{3}$ and $E_{4}$, if feasible, are unstable.

3. The equilibrium $E_{5}$ is related via transcritical bifurcations with equilibria $E_{6}$ and $E_{7}$.

4. The equilibrium $E_{6}$ is related via a transcritical bifurcation with the equilibrium $E^{*}$.

5. The equilibrium $E_{7}$ is related via a transcritical bifurcation with the equilibrium $E^{*}$.

6. The equilibrium $E^{*}$, if feasible, is locally asymptotically stable provided the following condition is satisfied:

$$
\frac{\lambda_{11}^{2} \alpha_{1}^{2} \lambda_{1} k_{12}}{\left(\alpha_{2}+\lambda_{11} \alpha_{1} B^{*}+\beta F^{*}\right)\left(k_{12}+k_{11} T^{*}\right)}<\frac{16 r \theta \lambda_{10} T^{*}}{K \delta^{2} \theta_{1} O^{*}}\left(\alpha_{0}+\frac{k_{1} k_{12} B^{*}}{\left(k_{12}+k_{11} T^{*}\right)^{2}}\right)
$$

The proof of this theorem is given in Appendix-B.

Theorem 2. The equilibrium $E^{*}$, if feasible, is non-linearly asymptotically stable inside the region of attraction $\Omega$ provided the following conditions are satisfied:

$$
\begin{array}{r}
{\left[\frac{k_{1} T^{*}}{k_{12}+k_{11} T^{*}} \frac{k_{11}\left(Q+\delta N_{m}\right)}{k_{12} \alpha_{0}+k_{11}\left(Q+\delta N_{m}\right)}\right]^{2}<\frac{\lambda_{10} \alpha_{0} T^{*}}{\lambda_{1}}} \\
\frac{\lambda_{1} \lambda_{11}^{2} \alpha_{1}^{2} O^{*}}{\lambda_{10} T^{*}}
\end{array}
$$

The proof of this theorem is given in Appendix- $C$.

Remark. This result prevents persistent oscillations of the system solutions. The above theorem implies that the discharge rate of domestic sewage $(\delta)$ and the carrying capacity of human population $(K)$ might have destabilizing effect on the dynamics of the system. Since $\delta$ appears in a Holling type II term, and therefore even if they grow large, the term will be bounded. Instead $K$ as 
well as $\delta$ appear in the denominator on the right hand side of (29). Thus $K$, appearing only in this equation, has a definite effect, to reduce the stability region; but since these are only sufficient conditions, this does not necessarily imply that on their violation, the equilibrium becomes unstable.

\section{$5 \quad$ Numerical simulations}

Here, we report the simulations performed to investigate the system behavior using Matlab vR2016a. The (hypothetical) parameter values are chosen within ranges defined in the existing literature $[19,8,20,21,37,17,18,7]$.

Table 1

Parameter values of the system (1) used in the simulations.

\begin{tabular}{|c|c|c|c|}
\hline $\begin{array}{l}\text { Variables/ } \\
\text { Parameters }\end{array}$ & Descriptions & Units & Values \\
\hline$N$ & Density of human population in the lake watershed & person $/ \mathrm{m}^{2}$ & - \\
\hline$T$ & Concentration of organic pollutants in the lake & $\mathrm{mg} / \mathrm{L}$ & - \\
\hline$B$ & Density of bacteria in the lake & cell/L & - \\
\hline$O$ & Concentration of DO in the lake & $\mathrm{mg} / \mathrm{L}$ & - \\
\hline$F$ & Density of fish population in the lake & fish $/ \mathrm{m}^{2}$ & - \\
\hline$r$ & Intrinsic growth rate of human population & 1/day & 4.843 \\
\hline$K$ & Carrying capacity of human population & $\operatorname{person} / \mathrm{m}^{2}$ & 0.624 \\
\hline$Q$ & Discharge rate of organic pollutants due to other sources & $\mathrm{mg} / \mathrm{L} /$ day & 8.922 \\
\hline$\delta$ & Discharge rate of organic pollutants due to human population & $\mathrm{mg} / \mathrm{L} /$ day/person & 9.134 \\
\hline$\alpha_{0}$ & Natural depletion rate of organic pollutants & $1 /$ day & 8.804 \\
\hline$k_{1}$ & Maximum uptake rate of organic pollutants by bacteria & $\mathrm{mg} /$ day/cell & 7.908 \\
\hline$k_{12}$ & Half saturation constant & $\mathrm{mg} / \mathrm{L}$ & 2.964 \\
\hline$k_{11}$ & Proportionality constant & - & 0.511 \\
\hline$\lambda_{1}$ & Proportionality constant & $\mathrm{cell} / \mathrm{mg}$ & 0.736 \\
\hline$\alpha_{1}$ & Natural death rate of bacteria & 1/day & 0.427 \\
\hline$\lambda_{10}$ & Death rate of bacteria due to intraspecific competition & $\mathrm{L} /$ cell/day & 8.278 \\
\hline$q$ & Input rate of DO & $\mathrm{mg} / \mathrm{L} /$ day & 16.913 \\
\hline$\alpha_{2}$ & Natural depletion rate of DO & $1 /$ day & 3.554 \\
\hline$\lambda_{11}$ & Proportionality constant & L/cell & 0.112 \\
\hline$\beta$ & Uptake rate of DO by fish & $\mathrm{m}^{2} /$ day/fish & 6.054 \\
\hline$\theta_{1}$ & Proportionality constant & fish $\mathrm{L} / \mathrm{m}^{2} / \mathrm{mg}$ & 0.884 \\
\hline$\alpha_{3}$ & Natural death rate of fish population & $1 /$ day & 6.407 \\
\hline$\beta_{10}$ & Death rate of fish population due to intraspecific competition & $\mathrm{m}^{2} /$ fish/day & 0.446 \\
\hline$\alpha$ & Rate of fishing by human & $\mathrm{m}^{2} /$ day/person & 2.721 \\
\hline$\theta$ & Proportionality constant & person/fish & 0.502 \\
\hline
\end{tabular}

For the set of parameter values given in Table 1, the conditions for the feasibility of the equilibrium $E^{*}$ are satisfied and its components are obtained as $N^{*}=0.81$ person $/ \mathrm{m}^{2}, T^{*}=1.74 \mathrm{mg} / \mathrm{L}, B^{*}=0.26$ cell $/ \mathrm{L}, O^{*}=1.69$ $\mathrm{mg} / \mathrm{L}$ and $F^{*}=1.05 \mathrm{fish} / \mathrm{m}^{2}$. For the set of parameter values in the Table 1 , eigenvalues of the matrix $J_{E^{*}}$ are found to be $-5.07 \pm 6.25 i,-2.37,-6.57$ and -9.06. The eigenvalues are either negative or with negative real parts, showing that the equilibrium $E^{*}$ is locally asymptotically stable. Also, the conditions for global stability of the equilibrium $E^{*}$ are satisfied for these parameter values. The stability of the coexistence equilibrium $E^{*}$ is shown in Fig. 2. Also, we observed a transcritical bifurcation arising between equilibria $E_{7}$ and $E^{*}$, obtained by the increase of both $Q$ and $\delta$ (figure not shown). Thus, the system moves from the bacteria-free equilibrium to coexistence of all populations. This 
is a reasonable transition since the bacteria growth depends on the organic pollutants. Other several transcritical bifurcations have been found relating the coexistence equilibrium with the equilibrium $E_{6}$ where the fish population is absent (figure not shown). There are also transcritical bifurcations between the bacteria-and-fish-free equilibrium $E_{5}$ with both fish-free $\left(E_{6}\right)$ and bacteriafree $\left(E_{7}\right)$ points (figure not shown).

In Figs. 3-6, we have shown the variations in human population, organic pollutants, bacteria, DO and fish population with respect to $K, Q, \delta$ and $\alpha$ for the set of parameter values given in Table 1 . We plotted all variables of the model (1) by varying two parameters at a time viz. $(K, \delta),(K, Q),(\delta, Q)$ and $(\alpha, Q)$ in the interval $[10,10] \times[10,10]$. From Fig. 3, we can see that on increasing the carrying capacity of human population, the human population increases but the fish population in the water body decreases quickly. Increasing both $K$ and $\delta$ lead to increase in the organic pollutants on the diagonal. It is apparent from Fig. 4 that increasing the values of $K$ leads to increase in human population, organic pollutants and bacteria but decrease in fish populations. On increasing the values of $Q$ and $\delta$, human population, DO and fish populations decrease along the diagonal of the domain, while organic pollutants and bacteria increase, Fig. 5. Considering the effect of the second human-related action modeled in the system, namely fishing, we observed that with an increase in the harvesting rate, $\alpha$, the human population attains a plateau, pollutants and bacteria are not affected, while the oxygen levels are enhanced, and of course the fish populations are severely reduced, reaching perhaps dangerously low levels, if the harvest rate is too large, Fig. 6.

\section{Sensitivity analysis}

Sensitivity analysis is a method for quantifying uncertainty in any type of complex model. Its objective is to identify the critical inputs, meaning all the parameters and initial conditions, of a model and to quantify how much input perturbations impact the system outcome. Following Marino et al. [42], from the system (1), we calculate the partial rank correlation coefficients (PRCCs) between the fish population and the parameters $K, Q, \delta, \alpha$ and $\beta$. Nonlinear and monotone relationships are observed for the fish population $(F)$ with the input parameters of the model (1), which is a prerequisite before computing PRCCs. We draw 100 samples from the biologically feasible range of the parameters of interest using the Latin Hypercube Sampling. The bar diagram of the PRCC values of the fish population against the important parameters of the model (1) is depicted in Fig. 7. PRCC values of these parameters with the fish population suggest that the discharge rate of pollutants from the sources

other than domestic sewage $(Q)$ has the maximum negative correlation with 
the fish population followed by the parameter $\delta$. The growth rate of the fish population due to DO $(\beta)$ has instead the maximum positive correlation with the fish population. Apart from these, the parameters $K$ and $\alpha$ have also significant negative correlations with the fish population.

\section{Discussions}

Water is an essential constituent for life on Earth. Water pollution due to human activities has caused a great deal of concern over the past few decades $[43,44]$. Urbanization has pushed the problem of the quality and quantity of water available for consumption to alarming levels, so that nowadays the existence of aquatic life is threatened, and as a consequence also human health is affected [45]. Increase in human population and economic development demand ever increasing amounts of water, but absence of sustainable management policies contributes to the continuous deterioration of aquatic ecosystems $[46,47]$. Large amounts of decaying biological materials in the water bodies lead to oxygen depletion, since micro-organisms use it for breaking down organic matter, and this results in fish population collapse [48,49], as the oxygen saturation level has an effect on growth and feed conversion ratios of fish [50-52]. An excess of decaying organic material in a body of water with infrequent or no turnover causes the rapid exhaustion of oxygen at the lower water levels $[2,53]$.

The situation of Ulsoor lake, Bengaluru, India shows that the lake is moderately to severely polluted entailing a decreased level of DO concentration in water. In turn, the water becomes unsafe for aquatic species living inside. The nonlinear mathematical model proposed and analyzed here incorporates the effects of human population on aquatic ecosystems that include fish. From the numerical simulations, we found that increasing both $K$ and $\delta$, the carrying capacity of the human population and the discharge rate of organic pollutants due to humans, or $K$ and $Q$, where $Q$ is the discharge rate of organic pollutants due to other sources, has the same effect on three of the five populations: human population, DO and fish population. Namely, the first two increase with $K$, the fish instead are depressed. These populations seem to be insensitive to changes in $\delta$ and $Q$. The organic pollutants and bacteria also both grow with $K$, but are also sensitive to changes in $\delta$ and $Q$. In fact, they grow faster if these parameter values are increasing. This is reasonable since $Q$ is a constant input into the system while the increase of $\delta$ depends in an indirect way on the carrying capacity of human population. This result is clearly apparent in Figs. 3 and 4 . We compare the ecosystem behavior when the parameters $\delta$ and $Q$ are both changed in Fig. 5. The simulation results show that increasing both $Q$ and $\delta$ leads to a somewhat slight decrease of $N, O$ and $F$ and

to a sensible increase of $T$ and $B$. Controlling the human-related activities 
that lead to pollutants discharges into the water bodies and favoring fisheries, within reasonable exploitation bounds, may be sensible means of preserving sufficient oxygen levels for the Ulsoor aquatic ecosystem sustainability, Fig. 7. The surveillance of fishing however seems important in order to prevent the fish disappearance by over exploitation of the resource.

The fish sensitivity to low levels of DO is species-specific, but most species begin to be affected when the concentration falls to values around $2-4 \mathrm{mg} / \mathrm{L}$, below which mortality usually occurs [54]. These low levels are frequently associated with phenomena such as hot, cloudy weather, organic overload, algae die-offs, or heavy thunderstorms [38]. Our study shows similar DO level when high amount of organic pollutants enter into the system. Bacterial decomposition of organic pollutants uses up very high amount of DO and leaves very little DO for organisms living in the aquatic system. This results in a typical hypoxic condition where organisms living in the water column start dying because of insufficient DO. Our results indicate that if we control the discharge of untreated domestic sewage and industrial effluents into the Ulsoor lake, the DO level can be maintained at adequate values. Theoretical and experimental studies suggest that to reduce fish mortality, a sufficient level of DO must be maintained $[2,17]$. Reducing untreated wastewater discharges therefore leads to aquatic fauna preservation. Removing hazardous inorganic and organic material from a water body could enhance the general state of the Ulsoor aquatic ecosystem and all the biota that reside within it.

\section{Compliance with Ethical Standards}

Funding The research work of PKT is funded by World Wide Style Project Second Edition of the Dipartimento di Matematica "Giuseppe Peano" of the Università di Torino. IMB and EV have been partially supported by the

project "Metodi numerici nelle scienze applicate" of the Dipartimento di Matematica "Giuseppe Peano".

Conflict of interests The authors declare that they have no conflicts of interest.

\section{References}

[1] Wu RSS, Zhou BS, Randall DJ, Woo NYS, Lam PKS, Aquatic hypoxia is an endocrine disruptor and impairs fish reproduction. Environ Sci Technol 37:11371141, 2003.

[2] Fundamentals of environmental measurements. http://www . fondriest. com/environmental-measurements/parameters/ water-quality/dissolved-oxygen. 
[3] Singh KP, Basant N, Malik A, Sinha S, Jain G, Multi-way modeling of wastewater data for performance evaluation of sewage treatment plant-A case study. Chemom Intell Lab Syst 95:18-30, 2009.

[4] Inmuong Y, Thailand water pollution crisis: a case on massive fish deaths in nam phong river. Fact Sheet Env Health 1(9), 1998.

[5] Theriault EJ, The dissolved oxygen demand of polluted waters. Public Health Bulletin No. 173. U.S. Public Health Service. Government Printing Office. Washington, D.C., 1927.

[6] Dauglas WJ, Honktao W, Fengting L, Impacts of population growth and economic development on water quality of a lake: Case study of lake Victoria Kenya water. Environ Sci Poll Res Int 21(8):5737-5746, 2014.

[7] Venturino E, Tiwari PK, Misra AK, Modeling the depletion of dissolved oxygen in a water body located near a city. Math Meth Appl Sci 40:1081-1094, 2017.

[8] Misra AK, Tiwari PK, A model for the effect of density of human population on the depletion of dissolved oxygen in a water body. Environ Dev Sustain 17:623-640, 2015.

[9] Streeter MW, Phelps EE, A study of the pollution and natural purification of the Ohio rivers. US Public Health Service. Public Heath Bulletin No. 146, 1925.

[10] Beck MB, Young PC, A dynamic model for DO-BOD relationship in a non-tidal stream. Water Res 9:769-776, 1975.

[11] Dobbins WE, BOD and oxygen relationship in streams. J San Eng Div Proc ASCE 90:53-78, 1964.

[12] Fair GM, The dissolved oxygen sag-an analysis. Int Adv Nondestr Test 11:445, 1939.

[13] Gates WE, Marler JT, Westeld JD, The application of bacterial process kinetics in stream simulation and stream analysis. Water Res 3:663-686, 1969.

[14] O'Connor DJ, The temporal and spatial distribution of dissolved oxygen in streams. Water Res 3:65-79, 1967.

[15] Rinaldi S, Soncini-sessa R, Stehfest H, Tamura H, Modeling and control of river quality. McGraw-Hill Inc. U.K., 1979.

[16] Stehfest H, Mathematical modelling of self-purification of rivers. Report KFK 1654 UF, Kernforschungszentrum Karlsruhe, Karlsruhe, 1973.

[17] Shukla JB, Misra AK, Chandra P, Mathematical modeling of the survival of a biological species in polluted water bodies. Diff Eqns Dyn Sys 15:209-230, 2007.

[18] Shukla JB, Misra AK, Chandra P, Mathematical modeling and analysis of the depletion of dissolved oxygen in eutrophide water bodies affected by organic pollutants. Nonlinear Anal RWA 9:1851-1865, 2008. 
[19] Misra AK, Chandra P, Shukla JB, Mathematical modeling and analysis of the depletion of dissolved oxygen in water bodies. Nonlinear Anal RWA 7:980-996, 2006 .

[20] Misra AK, Tiwari PK, Goyal A, Shukla JB, Modeling and analysis of the depletion of organic pollutants by bacteria with explicit dependence on dissolved oxygen. Nat Resour Model 27(2):258-273, 2014.

[21] Shukla JB, Goyal A, Tiwari PK, Misra AK, Modeling the role of dissolved oxygen dependent bacteria on biodegradation of organic pollutants. Inter $\mathrm{J}$ Biomath 7(1):1450008(1-16), 2014.

[22] Shukla JB, Misra AK, Chandra P, Modeling and analysis of the algal bloom in a lake caused by discharge of nutrients. Appl Math Comp 196(2):782-790, 2008.

[23] Misra AK, Modeling the depletion of dissolved oxygen due to algal bloom in a lake by taking Holling type-III interaction. Appl Math Comp 217:8367-8376, 2011 .

[24] Tiwari PK, Bulai IM, Misra AK, Venturino E, Modeling the direct and indirect effects of pollutants on the survival of fish in water bodies. J Biol Syst 25(3):521$543,2017$.

[25] Bangalore. https://en.wikipedia.org/wiki/Bangalore.

[26] Ulsoor lake. https://en.wikipedia.org/wiki/Ulsoor_Lake.

[27] Status of Ulsoor lake water quality between 1996-97. http://ces.iisc.ernet.in/energy/water/proceed/proceedings_text/ section6/paper12/section6paper12.htm\#up.

[28] Effects of aquatic pollution on fish and fisheries. https://www.scribd.com/ doc/7076320/EFFECT-OF-AQATIC-POLLUTION-ON-FISH-FISHERIES.

[29] Ulsoor lake study. http://wgbis.ces.iisc.ernet.in/energy/water/paper/ Tr-115/chapter3.htm.

[30] Schindler DW, Hesslein RH, Wagemann R, Broecker WS, Effects of acidification on mobilization of heavy metals and radionuclides from the sediments of a freshwater lake. Canadian Journal of Fisheries and Aquatic Sciences 37(3):373$377,1980$.

[31] Dissolved oxygen. Fundamentals of Environmental Measurements. http://www.fondriest.com/environmental-measurements/ parameters/water-quality/dissolved-oxygen/.

[32] In new SOS from Bengaluru lakes, thousands and thousands of dead fish. https://www.ndtv.com/bangalore-news/ dead-fish-thousands-of-them-show-up-around-bengaluru-lake-1284609.

[33] Millions

of fish are suddenly dying all over the planet. https://www.infowars.com/ mass-fish-deaths-millions-have-been-found-dead-all-over-the-world-in-the-past-month/. 
[34] Human population growth and oceans. http://www.biologicaldiversity.org/programs/population\_and \ _sustainability/oceans.

[35] Human impacts on marine environments. https://www.sciencelearn.org.nz/resources/ 144-human-impacts-on-marine-environments.

[36] Human population impacts on Columba rver basin fish and wildlife. https://www. nwcouncil.org/fw/isab/isab2007-3.

[37] Shukla JB, Lata K, Misra AK, Modeling the depletion of a renewable resource by population and industrialization: Effect of technology on its conservation. Nat Resour Model 24:242-267, 2011.

[38] Dissolved oxygen. Changing Hudson Project. Cary Institute of Ecosystem Studies. http://www.caryinstitute.org/sites/default/files/public/ downloads/curriculum-project/1C1\_dissolved \_oxygen\_reading.pdf.

[39] Freedman HI, So JWH, Global stability and persistence of simple food chains. Math Biosci 76:69-86, 1985.

[40] Hale JK, Ordinary differential equations, Wiley-Inscience, New York, 1969.

[41] LaSalle J, Lefschetz S, Stability by Liapunov's direct method with applocations. Academic Press, New York, 1961.

[42] Marino S, Hogue I, Ray C, Kirschner D, A methodology for performing global uncertainty and sensitivity analysis in systems biology. J Theor Biol 254:178196, 2008.

[43] Pimpunchat B, Sweatman WL, Wake GC, Triampo W, Parshotam A, A mathematical model for pollution in river and its remediation by aeration. Appl Math Letters 22:304-308, 2009.

[44] Schwarzenbach RP, Egli T, Hofstetter TB, Von Gunten U, Wehrli B, Global water pollution and human health. Annual Rev Environ Resour 35(1):109-136, 2010 .

[45] Munn RE, Fedorov V, The environmental assessment, IIASA Project Report, Laxenburg, Austria. 1:16, 1986.

[46] McDonel AJ, Oxygen budgets in macrophyte impacted streams. Water Res 16:1037-1046, 1982.

[47] Onyejekwe OO, Toolsi S, Certain aspects of Green element computational model for BOD-DO interaction. Adv Water Resour 24:125-131, 2001.

[48] August 2010 fish kill in Delaware Bay linked to high temperatures-low oxygen. http://www.newjerseynewsroom.com/science-updates/ fish-kill-in-delaware-bay-still-a-mystery-to-nj-dep. 
[49] Contaminated water kills fish in Central Illinois.

http://www . pantagraph.com/news/local/

contaminated-water-kills-fish-in-central-illinois/articlel

_a64ef8bc-bf50-11df-9804-001cc4c002e0.html.

[50] Mallya YJ, Thorarensen H, The effects of dissolved oxygen on fish growth in aquaculture. The United Nations University, Fisheries Training Programme, 2007.

http://www . unuftp.is/static/fellows/document/yovita07prf .pdf.

[51] Li WH, Unsteady dissolved-oxygen sag in a stream. J Sanit Engrg Div 88(3):7585, 1962.

[52] Li WH, Effects of dispersion on DO-Sag in uniform flow. J Sanit Engrg Div 98(1):169-182, 1972.

[53] Jha R, Ojha CSP, Bhatia KKS, On development of refined BOD and DO models for highly polluted Kali river in India. J Env Eng 113:839-852, 2007.

[54] Höhener P, Atteia O, Multidimensional analytical models for isotope ratios in groundwater pollutant plumes of organic contaminants undergoing different biodegradation kinetics. Adv Water Resour 33:740-751, 2010.

[55] Abate A, Tiwari A, Sastry S, Box invariance in biologically-inspired dynamical systems. Automatica 45:16011610, 2009.

\section{Appendix}

Appendix-A

System (1) can be rewritten in the following form:

$$
\begin{gathered}
\frac{d X}{d t}=C X+D \\
X=[N, T, B, O, F]^{T} \text { and } \\
C=\left[\begin{array}{ccccc}
r\left(1-\frac{N}{K}\right) & 0 & 0 & \theta \alpha N \\
\delta & -\left(\alpha_{0}+\frac{k_{1} B}{k_{12}+k_{11} T}\right) & 0 & 0 & 0 \\
0 & \frac{\lambda_{1} k_{1} B}{k_{12}+k_{11} T} & -\left(\alpha_{1}+\lambda_{10} B\right) & 0 & 0 \\
0 & 0 & 0 & -\left(\alpha_{2}+\lambda_{11} \alpha_{1} B+\beta F\right) & 0 \\
0 & 0 & 0 & \theta \beta F & -\left(\alpha_{3}+\beta_{10} F+\alpha N\right)
\end{array}\right]
\end{gathered}
$$


The vector $D=[0, Q, 0, q, 0]^{T}$ is positive. Note that $C(X)$ has all off-diagonal entries nonnegative, i.e., $C(X)$ is a Metzler matrix for all $X \in R_{+}^{5}$, since $D \geq 0$ system (1) is positively invariant in $R_{+}^{5}$ [55]. Therefore, any trajectory of the system (1) starting from an initial state in $R_{+}^{5}$ remains trapped forever in $R_{+}^{5}$.

Fourth equation of the system (1) is

$$
\frac{d O}{d t}=q-\alpha_{2} O-\lambda_{11} \alpha_{1} B O-\beta O F \leq q-\alpha_{2} O
$$

Hence, $0 \leq O(t) \leq \frac{q}{\alpha_{2}}+\left(O(0)-\frac{q}{\alpha_{2}}\right) e^{-\frac{q}{\alpha_{2}}}$. Therefore, as $t \rightarrow \infty, 0 \leq$ $O(t) \leq \frac{q}{\alpha_{2}}$ and for any $t>0,0 \leq O(t) \leq O_{m}$, where $O_{m}=\max \left\{\frac{q}{\alpha_{2}}, O(0)\right\}$.

From the last equation of the system (1), we get

$$
\frac{d F}{d t}=\theta_{1} \beta O F-\alpha_{3} F-\beta_{10} F^{2}-\alpha F N \leq \theta_{1} \beta O F-\beta_{10} F^{2} \leq F\left(\frac{\theta_{1} \beta q}{\alpha_{2}}-\beta_{10} F\right)
$$

By similar arguments, we have, for any $t>0,0 \leq F(t) \leq F_{m}$, where $F_{m}=$ $\max \left\{\frac{\theta_{1} \beta q}{\beta_{10} \alpha_{2}}, F(0)\right\}$.

From first equation of the system (1), we get

$$
\frac{d N}{d t}=r N\left(1-\frac{N}{K}\right)+\theta \alpha N F \leq N\left\{\left(r+\theta \alpha F_{m}\right)-\frac{r N}{K}\right\}
$$

Thus, we have, for any $t>0,0 \leq N(t) \leq N_{m}$, where $N_{m}=\max \left\{\frac{K\left(r+\theta \alpha F_{m}\right)}{r}, N(0)\right\}$.

From the second equation of the system (1), we get

$$
\frac{d T}{d t}=Q+\delta N-\alpha_{0} T-\frac{k_{1} T B}{k_{12}+k_{11} T} \leq Q+\delta N-\alpha_{0} T \leq Q+\delta N_{m}-\alpha_{0} T
$$

Thus, we have, for any $t>0,0 \leq T(t) \leq T_{m}$, where $T_{m}=\max \left\{\frac{Q+\delta N_{m}}{\alpha_{0}}, T(0)\right\}$.

From the third equation of the system (1), we get 


$$
\frac{d B}{d t}=\frac{\lambda_{1} k_{1} T B}{k_{12}+k_{11} T}-\alpha_{1} B-\lambda_{10} B^{2} \leq \frac{\lambda_{1} k_{1} T B}{k_{12}+k_{11} T}-\lambda_{10} B^{2} \leq B\left(\frac{\lambda_{1} k_{1} T_{m}}{k_{12}+k_{11} T_{m}}-\lambda_{10} B\right)
$$

Thus, for any $t>0,0 \leq B(t) \leq B_{m}$, where $B_{m}=\max \left\{\frac{\lambda_{1} k_{1} T_{m}}{\lambda_{10}\left(k_{12}+k_{11} T_{m}\right)}, B(0)\right\}$.

Therefore, all mathematically and biologically feasible solutions of the model system (1) enter the region $\Omega$; i.e., $\Omega$ is attracting. Hence, it is now sufficient to study the dynamical properties of the model (1) in $\Omega$.

\section{Appendix-B}

The Jacobian matrix ' $J$ ' for the model (1) may be obtained as follows:

$$
J=\left(\begin{array}{ccccc}
J_{11} & 0 & 0 & 0 & \theta \alpha N \\
\delta & -J_{22} & -J_{23} & 0 & 0 \\
0 & J_{32} & J_{33} & 0 & 0 \\
0 & 0 & -\lambda_{11} \alpha_{1} O & -J_{44} & -\beta O \\
-\alpha F & 0 & 0 & \theta_{1} \beta F & J_{55}
\end{array}\right),
$$

where

$$
\begin{aligned}
& J_{11}=r\left(1-\frac{2 N}{K}\right)+\theta \alpha F, J_{22}=\alpha_{0}+\frac{k_{1} k_{12} B}{\left(k_{12}+k_{11} T\right)^{2}}, J_{23}=\frac{k_{1} T}{k_{12}+k_{11} T}, \\
& J_{32}=\frac{\lambda_{1} k_{1} k_{12} B}{\left(k_{12}+k_{11} T\right)^{2}}, \quad J_{33}=\frac{\lambda_{1} k_{1} T}{k_{12}+k_{11} T}-\alpha_{1}-2 \lambda_{10} B \\
& J_{44}=\alpha_{2}+\lambda_{11} \alpha_{1} B+\beta F, \quad J_{55}=\theta_{1} \beta O-\alpha_{3}-\alpha N-2 \beta_{10} F .
\end{aligned}
$$

1. The eigenvalues of the matrix $J$ evaluated at the equilibrium $E_{1}$ are given by

$$
r,-\alpha_{0}, \frac{\lambda_{1} k_{1} Q}{k_{12} \alpha_{0}+k_{11} Q}-\alpha_{1},-\alpha_{2}, \frac{\theta_{1} \beta q}{\alpha_{2}}-\alpha_{3} .
$$

Since one eigenvalue of the matrix $J_{E_{1}}$ is always positive, the equilibrium $E_{1}$ is always unstable.

2. Three eigenvalues of the matrix $J$ evaluated at the equilibrium $E_{2}$ are given by

$$
r,-\left(\alpha_{2}+\lambda_{11} \alpha_{1} B_{2}\right), \theta_{1} \beta O_{2}-\alpha_{3}
$$


and two are given by the roots of the following equation:

$$
\begin{aligned}
x^{2}+\left(\alpha_{0}+\right. & \left.\frac{k_{1} k_{12} B_{2}}{\left(k_{12}+k_{11} T_{2}\right)^{2}}+\lambda_{10} B_{2}\right) x \\
& +\lambda_{10} B_{2}\left(\alpha_{0}+\frac{k_{1} k_{12} B_{2}}{\left(k_{12}+k_{11} T_{2}\right)^{2}}\right)+\frac{\lambda_{1} k_{1} k_{12} B_{2}}{\left(k_{12}+k_{11} T_{2}\right)^{2}} \frac{k_{1} T_{2}}{k_{12}+k_{11} T_{2}}=0 .
\end{aligned}
$$

As one eigenvalue of the matrix $J_{E_{2}}$ is always positive, the equilibrium $E_{2}$ is unconditionally unstable.

3. Three eigenvalues of the matrix $J$ evaluated at the equilibrium $E_{3}$ are given by

$$
r+\theta \alpha F_{3},-\alpha_{0}, \frac{\lambda_{1} k_{1} Q}{k_{12} \alpha_{0}+k_{11} Q}-\alpha_{1}
$$

and two are given by roots of the following equation:

$$
x^{2}+\left(\alpha_{2}+\beta F_{3}+\beta_{10} F_{3}\right) x+\beta_{10} F_{3}\left(\alpha_{2}+\beta F_{3}\right)+\theta_{1} \beta^{2} O_{3} F_{3}=0 .
$$

Clearly, one eigenvalue of the matrix $J_{E_{3}}$ is positive if the equilibrium $E_{3}$ is feasible.

4. One eigenvalue of the matrix $J$ evaluated at $E_{4}$ is $r+\theta \alpha F_{4}$, two are roots of the following equation:

$$
\begin{aligned}
x^{2}+\left(\alpha_{0}+\right. & \left.\frac{k_{1} k_{12} B_{4}}{\left(k_{12}+k_{11} T_{4}\right)^{2}}+\lambda_{10} B_{4}\right) x \\
& +\lambda_{10} B_{4}\left(\alpha_{0}+\frac{k_{1} k_{12} B_{4}}{\left(k_{12}+k_{11} T_{4}\right)^{2}}\right)+\frac{\lambda_{1} k_{1} k_{12} B_{4}}{\left(k_{12}+k_{11} T_{4}\right)^{2}} \frac{k_{1} T_{4}}{k_{12}+k_{11} T_{4}}=0
\end{aligned}
$$

and the other two are roots of the following equation:

$$
\begin{aligned}
x^{2}+\left\{\alpha_{2}+\right. & \left.\lambda_{11} \alpha_{1} B_{4}+\beta F_{4}+\beta_{10} F_{4}\right\} x \\
& +\beta_{10} F_{4}\left(\alpha_{2}+\lambda_{11} \alpha_{1} B_{4}+\beta F_{4}\right)+\theta_{1} \beta^{2} O_{4} F_{4}=0 .
\end{aligned}
$$

Clearly, one eigenvalue of the matrix $J_{E_{4}}$ is positive if the equilibrium $E_{4}$ is feasible, compare (9).

5. The eigenvalues of the matrix $J$ evaluated at the equilibrium $E_{5}$ are given by 


$$
-r,-\alpha_{0}, \frac{\lambda_{1} k_{1}(Q+\delta K)}{k_{12} \alpha_{0}+k_{11}(Q+\delta K)}-\alpha_{1},-\alpha_{2}, \frac{\theta_{1} \beta q}{\alpha_{2}}-\alpha_{3}-\alpha K .
$$

Clearly, one eigenvalue of the matrix $J_{E_{5}}$ is positive if either equilibrium $E_{6}$ or $E_{7}$ is feasible.

6. Three eigenvalues of the matrix $J$ evaluated at the equilibrium $E_{6}$ are given by

$$
-r,-\left(\alpha_{2}+\lambda_{11} \alpha_{1} B_{6}\right), \theta_{1} \beta O_{6}-\alpha_{3}-\alpha K
$$

and two are given by the roots of the following equation:

$$
\begin{aligned}
x^{2}+ & \left(\alpha_{0}+\frac{k_{1} k_{12} B_{6}}{\left(k_{12}+k_{11} T_{6}\right)^{2}}+\lambda_{10} B_{6}\right) x \\
& +\lambda_{10} B_{6}\left(\alpha_{0}+\frac{k_{1} k_{12} B_{6}}{\left(k_{12}+k_{11} T_{6}\right)^{2}}\right)+\frac{\lambda_{1} k_{1} k_{12} B_{6}}{\left(k_{12}+k_{11} T_{6}\right)^{2}} \frac{k_{1} T_{6}}{k_{12}+k_{11} T_{6}}=0 .
\end{aligned}
$$

Clearly, one eigenvalue of the matrix $J_{E_{6}}$ is positive if the equilibrium $E^{*}$ is feasible.

7. Two eigenvalues of the matrix $J$ evaluated at the equilibrium $E_{7}$ are given by

$$
-\alpha_{0}, \frac{\lambda_{1} k_{1} T_{7}}{k_{12}+k_{11} T_{7}}-\alpha_{1}
$$

and the other three are given by the roots of the following equation:

$$
\begin{aligned}
x^{3}+ & \left(\frac{r N_{7}}{K}+\alpha_{2}+\beta F_{7}+\beta_{10} F_{7}\right) x^{2} \\
+ & \left\{\left(\alpha_{2}+\beta F_{7}+\beta_{10} F_{7}\right) \frac{r N_{7}}{K}+\beta_{10} F_{7}\left(\alpha_{2}+\beta F_{7}\right)+\theta_{1} \beta^{2} O_{7} F_{7}+\theta \alpha^{2} N_{7} F_{7}\right\} x \\
& +\left\{\beta_{10} F_{7}\left(\alpha_{2}+\beta F_{7}\right)+\theta_{1} \beta^{2} O_{7} F_{7}\right\} \frac{r N_{7}}{K}+\theta \alpha^{2} N_{7} F_{7}\left(\alpha_{2}+\beta F_{7}\right)=0 .
\end{aligned}
$$

Clearly, one eigenvalue of the matrix $J_{E_{7}}$ is positive if the equilibrium $E^{*}$ is feasible.

8. To study the local stability of the equilibrium $E^{*}$, we linearize system (1) by using the transformations

$$
N=N^{*}+n, T^{*}=T+\tau, B^{*}=B+b, O^{*}=O+o, F^{*}=F+f .
$$


Now, we consider the following positive definite function:

$$
W=\frac{1}{2}\left(\frac{1}{N^{*}} n^{2}+m_{1} \tau^{2}+\frac{m_{2}}{B^{*}} b^{2}+m_{3} o^{2}+\frac{m_{4}}{F^{*}} f^{2}\right),
$$

and use the linearized system of (1) to get,

$$
\begin{aligned}
\frac{d W}{d t}= & -\frac{r}{K} n^{2}-m_{1}\left(\alpha_{0}+\frac{k_{1} k_{12} B^{*}}{\left(k_{12}+k_{11} T^{*}\right)^{2}}\right) \tau^{2}-m_{2} \lambda_{10} b^{2} \\
& -m_{3}\left(\alpha_{2}+\lambda_{11} \alpha_{1} B^{*}+\beta F^{*}\right) o^{2}-m_{4} \beta_{10} f^{2}+\left[\theta \alpha-m_{4} \alpha\right] n f \\
& +\left[m_{1} \delta\right] \tau n+\left[\frac{m_{2} \lambda_{1} k_{1} k_{12}}{\left(k_{12}+k_{11} T^{*}\right)^{2}}-\frac{m_{1} k_{1} T^{*}}{k_{12}+k_{11} T^{*}}\right] \tau b \\
& -m_{3} \lambda_{11} \alpha_{1} O^{*} b o+\left[m_{4} \theta_{1} \beta-m_{3} \beta O^{*}\right) o f .
\end{aligned}
$$

Choose $m_{4}=\frac{1}{\theta}, m_{2}=\frac{m_{1} T^{*}\left(k_{12}+k_{11} T^{*}\right)}{\lambda_{1} k_{12}}$ and $m_{3}=\frac{\theta_{1}}{\theta O^{*}}$, we have

$$
\begin{aligned}
\frac{d W}{d t}= & -\frac{r}{K} n^{2}-m_{1}\left(\alpha_{0}+\frac{k_{1} k_{12} B^{*}}{\left(k_{12}+k_{11} T^{*}\right)^{2}}\right) \tau^{2}-\frac{m_{1} \lambda_{10} T^{*}\left(k_{12}+k_{11} T^{*}\right)}{\lambda_{1} k_{12}} b^{2} \\
& -\frac{\theta_{1}\left(\alpha_{2}+\lambda_{11} \alpha_{1} B^{*}+\beta F^{*}\right)}{\theta O^{*}} o^{2}-\frac{\beta_{10}}{\theta} f^{2}+\left[m_{1} \delta\right] \tau n-\frac{\theta_{1} \lambda_{11} \alpha_{1}}{\theta} b o .
\end{aligned}
$$

Now $\frac{d W}{d t}$ can be made negative definite, if the condition (27) is satisfied.

Appendix-C

We consider the following positive definite function, where $m_{i}, i=1, \ldots, 4$ are positive constants to be chosen later:

$$
\begin{aligned}
V=(N- & \left.N^{*}-N^{*} \ln \frac{N}{N^{*}}\right)+\frac{1}{2} m_{1}\left(T-T^{*}\right)^{2}+m_{2}\left(B-B^{*}-B^{*} \ln \frac{B}{B^{*}}\right) \\
+ & \frac{1}{2} m_{3}\left(O-O^{*}\right)^{2}+m_{4}\left(F-F^{*}-F^{*} \ln \frac{F}{F^{*}}\right) .
\end{aligned}
$$

Differentiating the above equation with respect to time ' $t$ ' along the solutions of model (1) and rearranging the terms, we have

$$
\dot{V}=-\frac{r}{K}\left(N-N^{*}\right)^{2}-m_{1}\left[\alpha_{0}+\frac{k_{1} k_{12} B}{\left(k_{12}+k_{11} T\right)\left(k_{12}+k_{11} T^{*}\right)}\right]\left(T-T^{*}\right)^{2}
$$




$$
\begin{aligned}
& -m_{2} \lambda_{10}\left(B-B^{*}\right)^{2}-m_{3}\left(\alpha_{2}+\lambda_{11} \alpha_{1} B+\beta F\right)\left(O-O^{*}\right)^{2}-m_{4} \beta_{10}\left(F-F^{*}\right)^{2} \\
& +\left[\theta \alpha-m_{4} \alpha\right]\left(N-N^{*}\right)\left(F-F^{*}\right)+\left[m_{1} \delta\right]\left(N-N^{*}\right)\left(T-T^{*}\right) \\
& +\left[\frac{m_{2} \lambda_{1} k_{1} k_{12}}{\left(k_{12}+k_{11} T\right)\left(k_{12}+k_{11} T^{*}\right)}-\frac{m_{1} k_{1} T^{*}}{k_{12}+k_{11} T^{*}}\right]\left(T-T^{*}\right)\left(B-B^{*}\right) \\
& -m_{3} \lambda_{11} \alpha_{1} O^{*}\left(B-B^{*}\right)\left(O-O^{*}\right)+\left[m_{4} \theta_{1} \beta-m_{3} \beta O^{*}\right]\left(O-O^{*}\right)\left(F-F^{*}\right) .
\end{aligned}
$$

Choosing $m_{4}=\frac{1}{\theta}, m_{2}=\frac{m_{1} T^{*}}{\lambda_{1}}$ and $m_{3}=\frac{\theta_{1}}{\theta O^{*}}$, we have

$$
\begin{aligned}
\dot{V}= & -\frac{r}{K}\left(N-N^{*}\right)^{2}-m_{1}\left[\alpha_{0}+\frac{k_{1} k_{12} B}{\left(k_{12}+k_{11} T\right)\left(k_{12}+k_{11} T^{*}\right)}\right]\left(T-T^{*}\right)^{2} \\
& -\frac{m_{1} \lambda_{10} T^{*}}{\lambda_{1}}\left(B-B^{*}\right)^{2}-\frac{\theta_{1}}{\theta O^{*}}\left(\alpha_{2}+\lambda_{11} \alpha_{1} B+\beta F\right)\left(O-O^{*}\right)^{2}-\frac{\beta_{10}}{\theta}\left(F-F^{*}\right)^{2} \\
& +\left[m_{1} \delta\right]\left(N-N^{*}\right)\left(T-T^{*}\right)-m_{1}\left[\frac{k_{1} T^{*}}{k_{12}+k_{11} T^{*}} \frac{k_{11} T}{k_{12}+k_{11} T}\right]\left(T-T^{*}\right)\left(B-B^{*}\right) \\
& -\frac{\theta_{1} \lambda_{11} \alpha_{1}}{\theta}\left(B-B^{*}\right)\left(O-O^{*}\right) .
\end{aligned}
$$

Now $\frac{d V}{d t}$ can be made negative definite inside the region of attraction $\Omega$, if the conditions (28) and (29) are satisfied. 


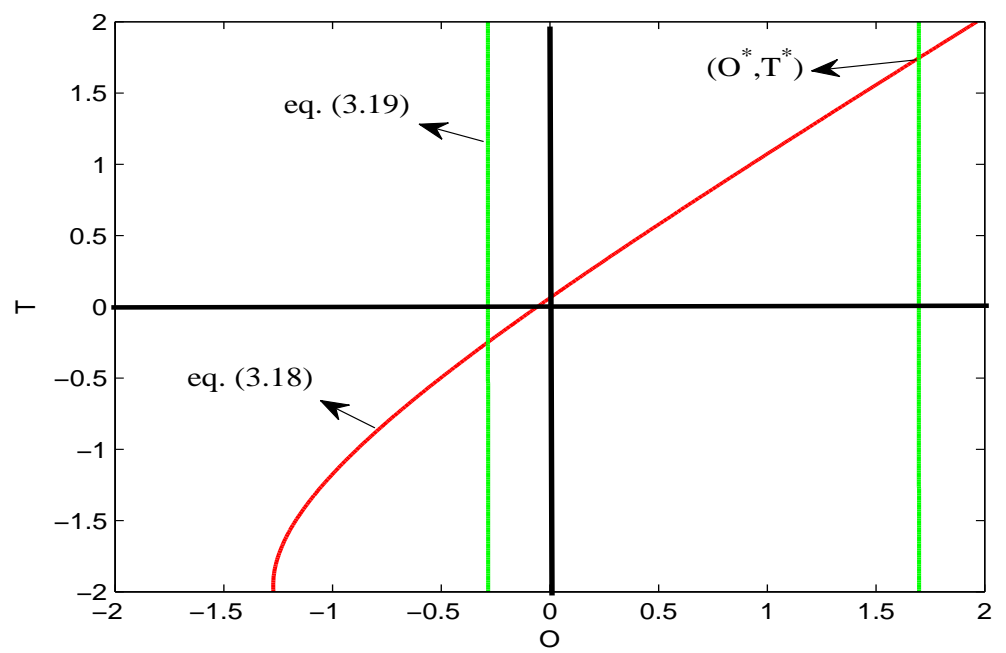

Fig. 1. Existence of $\left(O^{*}, T^{*}\right)$, the intersection point of the isoclines (20) and (21), for the set of parameter values given in Table 1.
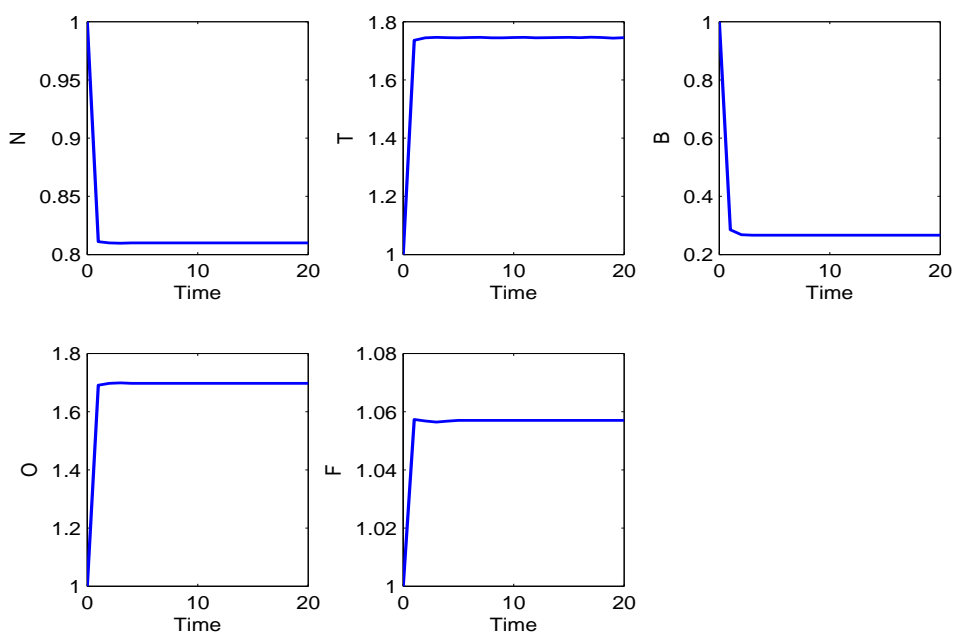

Fig. 2. Stability of the coexistence equilibrium $E^{*}$ for the set of parameter values in the Table 1. 

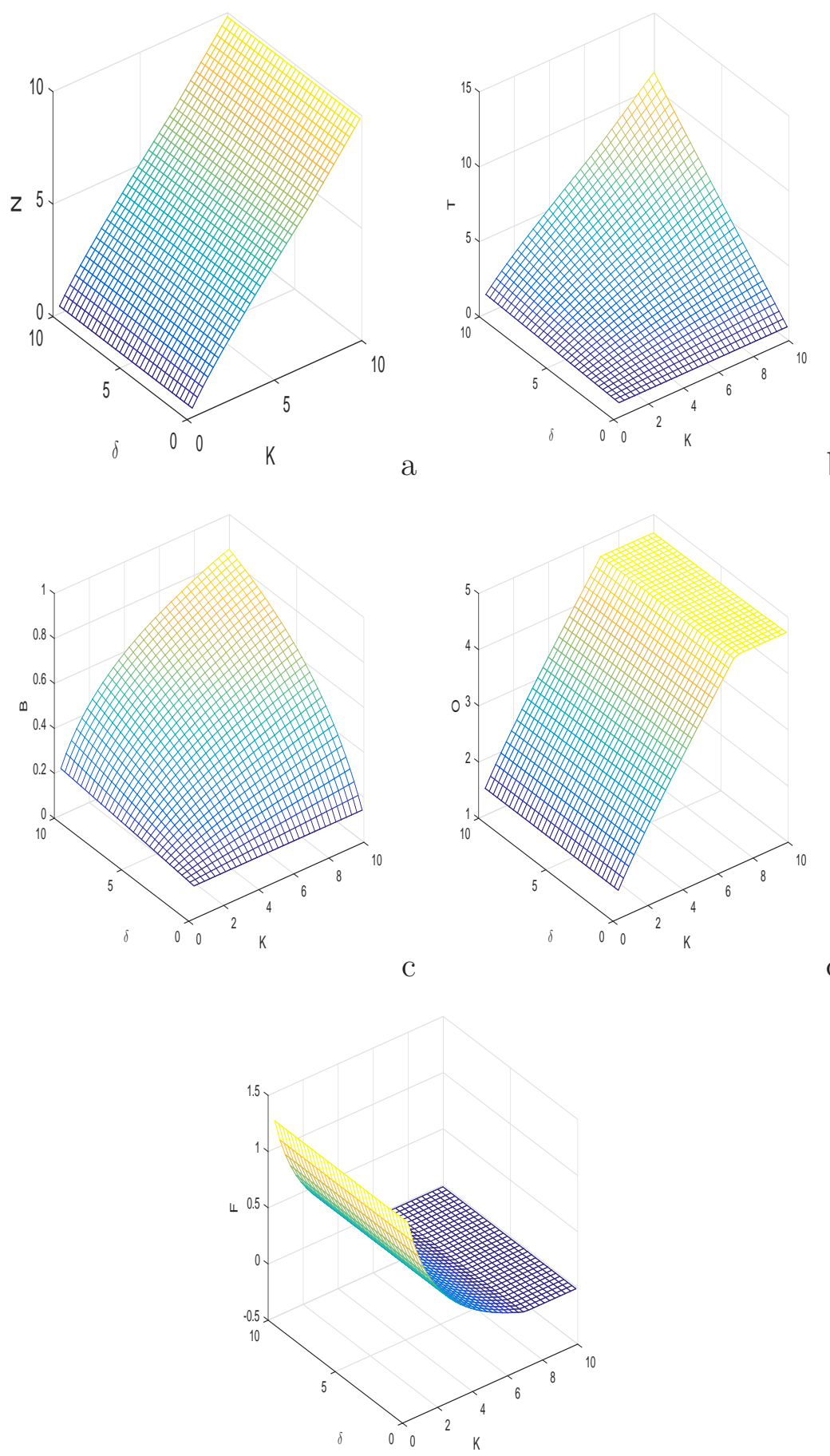

$\mathrm{e}$

Fig. 3. Variation in (a) human population, (b) organic pollutants, (c) bacteria, (d) DO and (e) fish populations with respect to $K$ and $\delta$. Rest of the parameter values are the same as in the Table 1. 

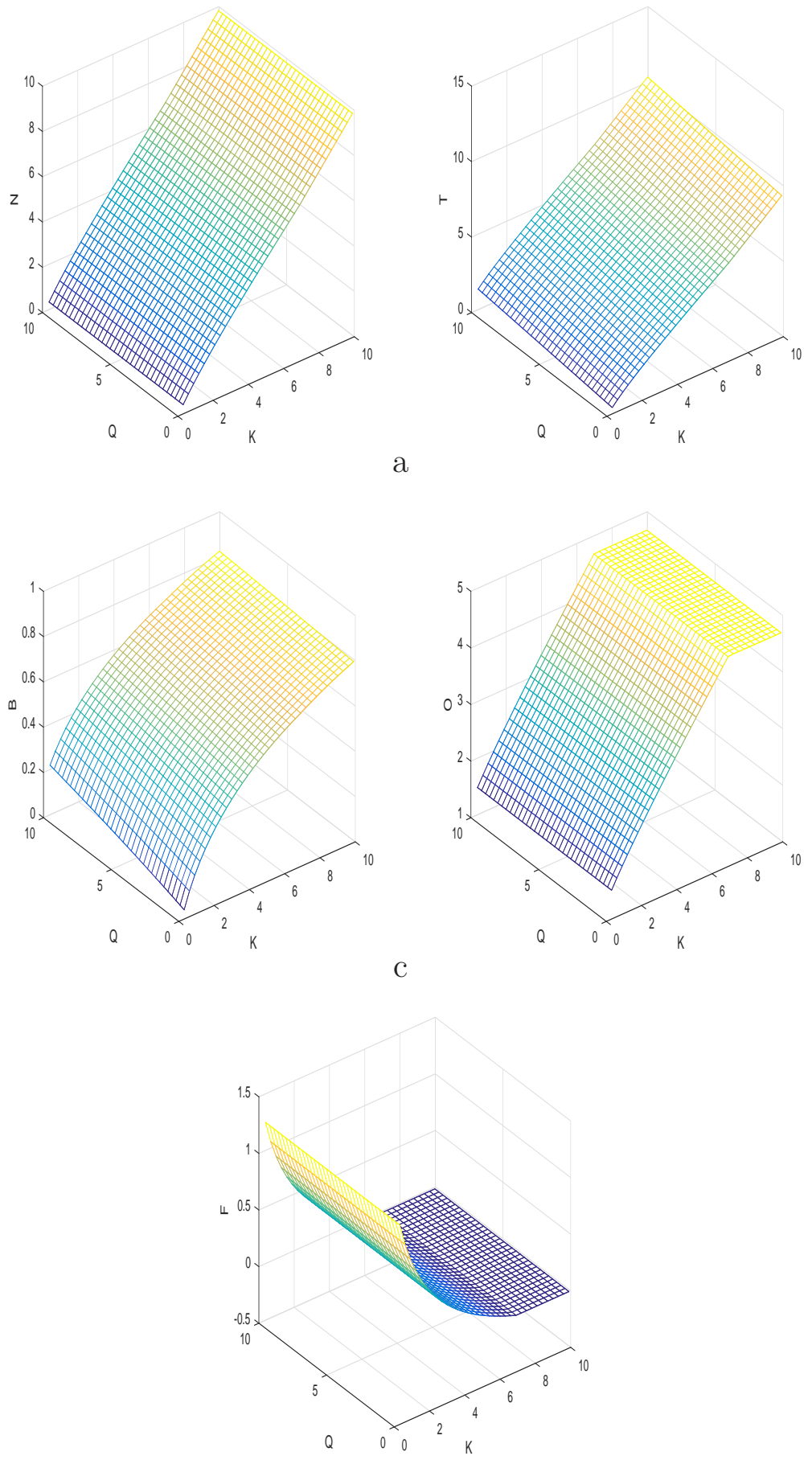

Fig. 4. Variation in (a) human population, (b) organic pollutants, (c) bacteria, (d) $\mathrm{DO}$ and (e) fish populations with respect to $K$ and $Q$. Rest of the parameter values are the same as in the Table 1. 

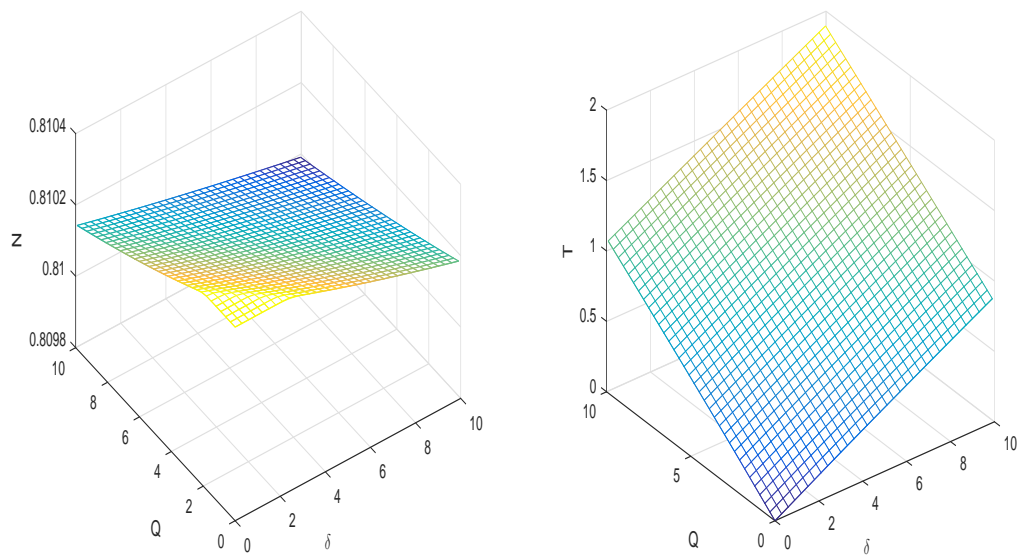

a
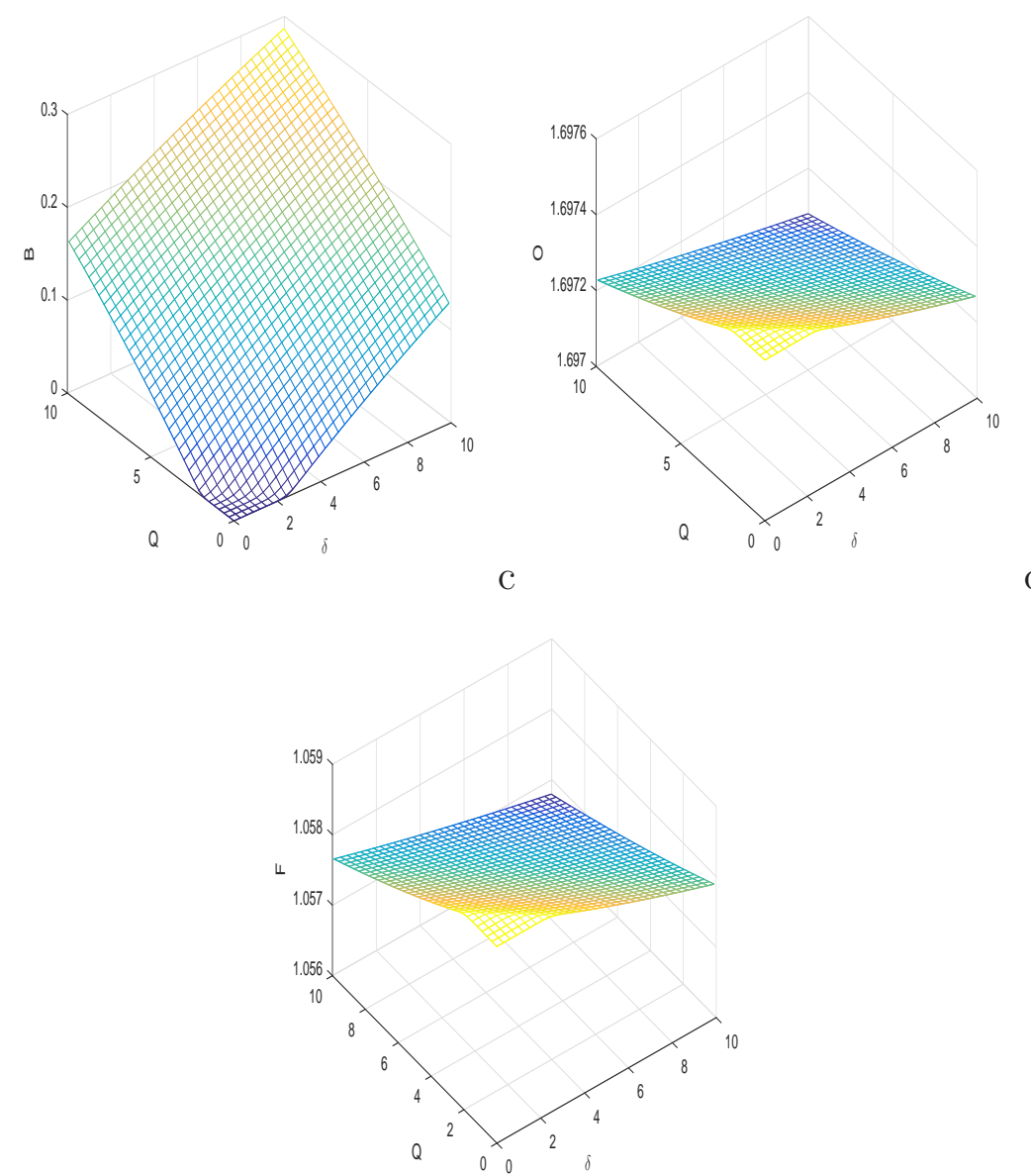

e

Fig. 5. Variation in (a) human population, (b) organic pollutants, (c) bacteria, (d) DO and (e) fish populations with respect to $Q$ and $\delta$. Rest of the parameter values are the same as in the Table 1. 

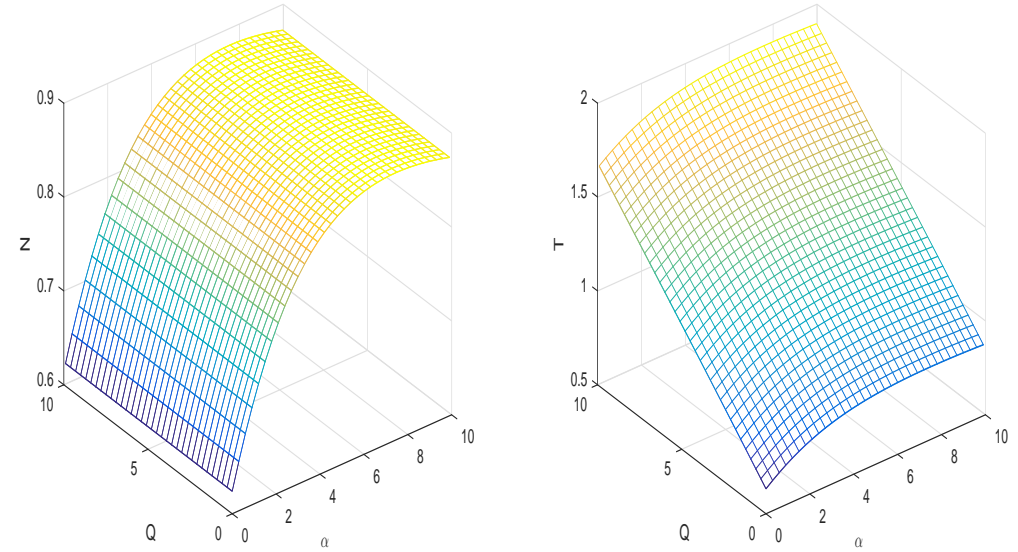

a
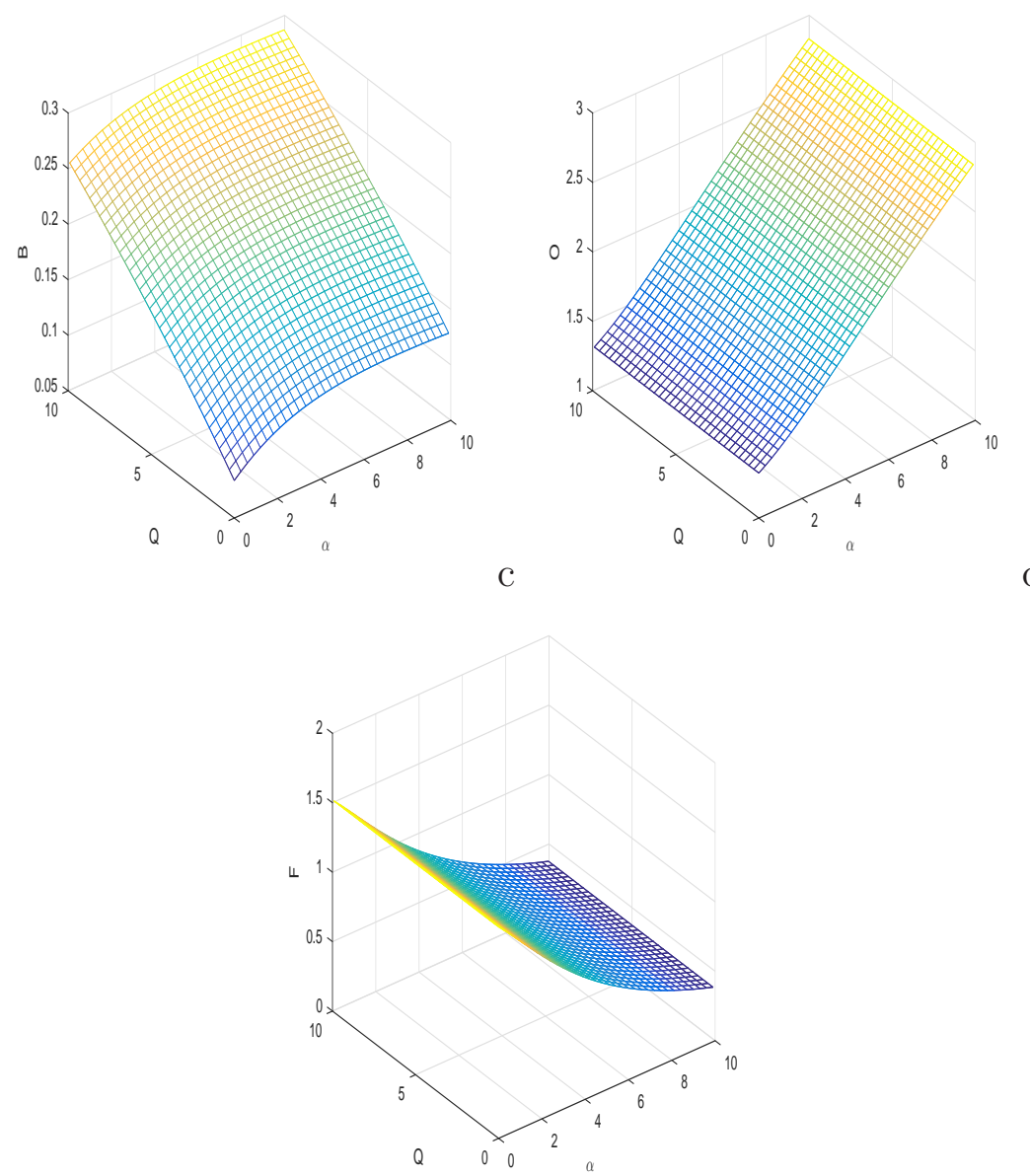

Fig. 6. Variation in (a) human population, (b) organic pollutants, (c) bacteria, (d) DO and (e) fish populations with respect to $\alpha$ and $Q$. Rest of the parameter values are the same as in the Table 1. 


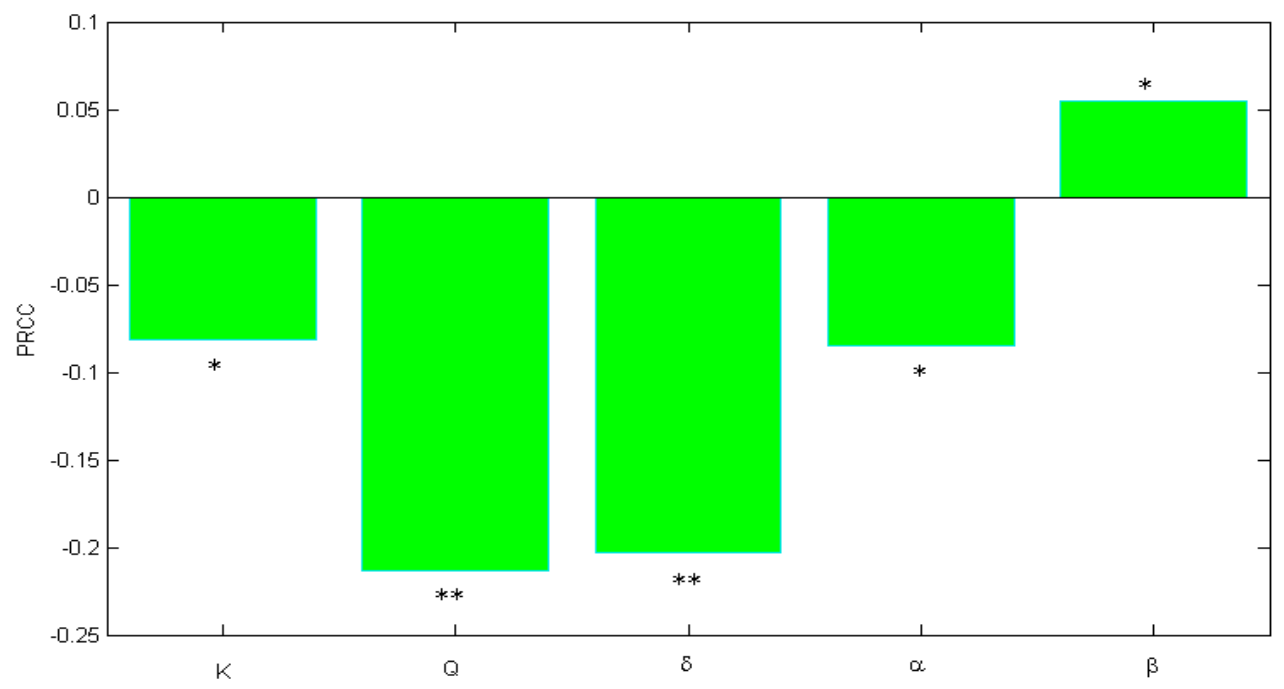

Fig. 7. Effect of uncertainty of the system (1) on the fish population. 100 samples for each parameters were drawn using Latin Hypercube Sampling Techniques. Significant parameters are indicated as ** $(|P R C C|>0.2)$ and * $(|P R C C|>0.05)$ for $p<0.05$. 